\title{
Effects of doxorubicin on the developing brain of albino mice embryos
}

\author{
Yogendra Singh ${ }^{1, *}$, Ramji $^{2}$, G.L. Shah ${ }^{3}$ \\ ${ }^{1}$ Assistant Professor, ${ }^{2,3}$ Professor, Dept. of Anatomy, ${ }^{1,2}$ BRD Medical College, Gorakhpur, Uttar Pradesh, ${ }^{3}$ M. S. Banaras Hindu \\ University, Varanasi, Uttar Pradesh, India
}

*Corresponding Author:

Email: yogisingh99@gmail.com

\begin{abstract}
Introduction: Doxorubicin is an anthracycline antineoplastic drug. It has been widely used in the treatment of many malignancies including haematological malignancies, soft tissues sarcomas, breast cancer and neuro-blastoma etc. The doxorubicin rat model is an established model which encompasses spectrum of anomalies seen in VACTERAL associations and has similarities to human VACTER anomalies. The aim of present study is to support the anomalies produced by doxorubicin in albino mice embryos.

Material and Methods: The present study was conducted in the department of anatomy, IMS, BHU Varanasi, U.P, on fifty female albino mice of an average age of 80 to 100 days, kept in plastic cage with male (3female: 1 male) in aseptic air condition. After confirming the pregnancy, the drug was administered intraperitoneally on the $8^{\text {th }}$ day of gestation in a dose of $3 \mathrm{mg} / \mathrm{kg}$ body weight. The foetuses were collected by exteriorization of uterine horn on $19^{\text {th }}$ day of gestation and examined for congenital anomalies.

Observations: Foetuses were divided into two groups, control and treated. Out of 239 treated foetuses, 25 foetuses were found dead, 106 foetuses showed congenital anomalies and the rest 108 foetuses were found normal. The brains of treated foetuses were smaller and reduced in weight (microcephaly) as compared to average weight and size of brain of control foetuses. On histological examination, cerebrum and cerebellum showed degeneration and aggregation of neuronal cells.

Conclusions: The drug was found to be lethal as well as teratogenic in developing mice embryos. Since, mice are the foremost mammal model for researchers; the present study also establishes doxorubicin mouse model support to the well established adriamycine rat model for VACTERL anomalies.
\end{abstract}

Keywords: Doxorubicin (Adriamycine), VACTERL (Vertebral, anal, Cardiac, Tracheal, Oesophageal, Renal \& limb) anomalies.

\section{Introduction}

Congenital anomaly is defined as a structural / functional defect present at birth and represents abnormal developmental processes of the developing embryos and so, these are the major public health problems. Though, the infant mortality rate has fallen throughout the world in the past decades due to better health care, improvements in living standards and awareness of harmful drugs during pregnancy but still, worldwide, congenital anomalies are a leading cause of infant mortality.

According to the organisation of teratology information specialists, the pregnancies (ies) of all women have 3 to $5 \%$ chance of having a baby with birth defects. It has been estimated that a malformed child is being delivered every 30 seconds in this world (Nishimura 1964). ${ }^{1}$ Women whose pregnancies are unintended and unexpected are more likely to be exposed to a wide range of potential teratogen (Denial et al $2003,{ }^{2}$ Naomi et al $2003^{3}$ ).

Now the causes of congenital malformations have a wide spectrum, which includes various genetic diseases, environmental factors, an excess of radiation, infections, chemical insult and almost every drug.

Doxorubicin marketed as trade name of Adriamycin. It is an anthracycline antibiotic used as an anti-cancerous drug in the treatment of a wide range of cancers including, haematological malignancies, breast cancer and soft tissues sarcomas.
The exact mechanism of action of doxorubicin is complex. Primarily It inhibits the enzyme topoisomerase which unwinds DNA for transcription preventing the DNA double helix from being resealed and thereby stopping the processes of replication (Goodman \& Gilman $11^{\text {th }}$ edition). ${ }^{4}$ Anthracycline by virtue of their unique groups also generates free radicals in solution of both normal and malignant tissuses (Meyers 1988, ${ }^{5}$ Gewirtz 19996).

\section{Material and Methods}

The present study was conducted in the department of anatomy, IMS, BHU Varanasi, U.P, on fifty female albino mice of an average age of 80 to 100 days and weight $20 \mathrm{~g}$. Mice were kept in aseptic air condition room overnight in plastic cage in the ratio of 3:1 (3 female:1male). Next morning pregnancy was confirmed by seeing vaginal plaque and making it's smear on glass slide. If sperms are seen in this smear under light microscope, it was considered as day one of pregnancy. After confirming the pregnancy the mice was kept separately in individual cage and the doxorubicin was administered intraperitoneally by tuberculin syringe on the $8^{\text {th }}$ day of gestation in a dose of $3 \mathrm{mg} / \mathrm{kg}$ body weight after dilution with normal saline. The foetuses were collected by exteriorization of uterine horn after opening the abdomen by midline caesarean incision on the $19^{\text {th }}$ day of gestation (full term pregnancy). The sacs of uterine horns were inspected for sites of 
resumptions/dead and viable foetuses, and examined for external congenital anomalies. The weights of foetuses were recorded by electronic weighing balance. After external examination foetuses were fixed in $10 \%$ formalin solution. There after brain was dissected out and it's antero-posterior and transverse diameter were measured by placing the brain on graph paper. The brain tissue processing and embedding done for $\mathrm{H} \& \mathrm{E}$ stain. Photomicrographs were taken with the help of digital light microscope connected with computer.

\section{Observations}

Foetuses were divided into two groups control and treated. Out of 239 treated foetuses, 25 foetuses were found dead, 106 foetuses showed congenital anomalies and rest 108 foetuses were found normal. The average weight of control brain was $0.046 \mathrm{~g}$ (ranging 0.035 -
$0.058)$, while that of treated brain was $0.037 \mathrm{~g}(0.030$ $0.046)$, which is very less and highly significant ( $p$ value $<001)$.

The average antero-posterior and transverse diameter of brain in control foetuses was $8.07 \mathrm{~mm}$ and $4.66 \mathrm{~mm}$ respectively, while that $\mathrm{A}-\mathrm{P}$ and transverse diameter of brain in treated fetuses was $6.25 \mathrm{~mm}$ and $3.85 \mathrm{~mm}$ respectively. The above observations indicate that brains of treated foetuses were smaller and reduced in weight (microcephaly).

On microscopic examination of $\mathrm{H} \& \mathrm{E}$ stained transverse sections of treated cerebrum showed degeneration and aggregation of neuronal cells, due to which normal architecture of cerebrum was lost. Cerebellum of treated foetuses showed severe degenerative changes in neuronal cells and derangement of normal pattern.

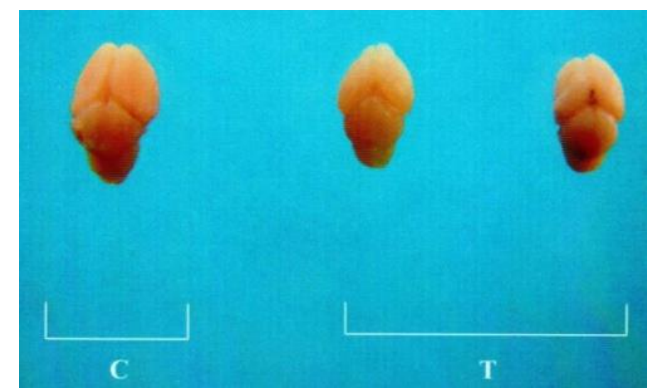

Fig. 1: Gross appearance of brain of treated mice embryos showing reduced size of drug-treated brain in comparison to control mice embryos
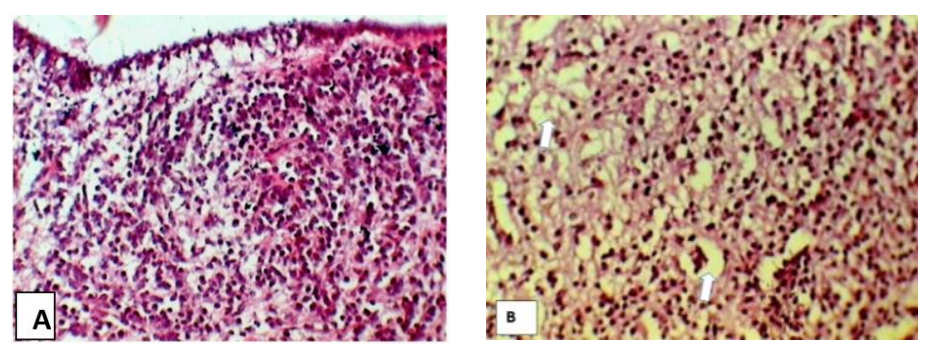

Fig. 2: Photomicrograph of transverse section of cerebrum of control \& treated mice embryo (H \&E stain $x$ 400). (A) Control cerebrum of mice embryo showing normal architecture; (B) Drug-treated cerebrum of mice embryo showing pyknotic degeneration of cells and change of normal architecture.
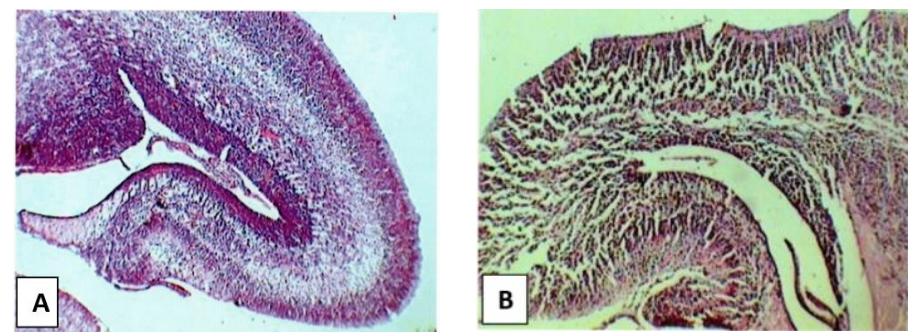

Fig. 3: Photomicrograph of Transverse section of cerebellum of control \& treated mice embryo (H \& $\mathrm{E}$ stain x100). (A) Control cerebellum showing normal architecture; (B) Drug-treated cerebellum showing severe degeneration of purkinje cells and change of normal architecture

\section{Discussion}

The present study has demonstrated that Doxorubicin is teratogenic to albino mice, when administered intraperitoneal on the $8^{\text {th }}$ day of gestation in a dose of $3 \mathrm{mg} / \mathrm{kg}$ body weight. The dose and timing of exposure of the foetuses to doxorubicin is critical in 
producing malformations. Orford et al, $1999^{7}$ reported that the administration of Adriamycine in a dose above $2.5 \mathrm{mg} / \mathrm{kg}$ in too early phage of gestation leads to death or resorption of foetuses and dose below $1.5 \mathrm{mg} / \mathrm{kg}$ administered late in gestation do not produces expected malformations. Gllick et al, $2008^{8}$ reported high rate of resorption with early administration of Adriamycine. The lethal dose (LD50) after a single intravenous bolus injection of doxorubicin to rats, mice and rabbits were $12.6,9.4$ and $6 \mathrm{mg} / \mathrm{kg}$, respectively. Therefore it is clear that for the current study doxorubicin injected intraperitoneally in doses of $3 \mathrm{mg} / \mathrm{kg}$ body weight at $8^{\text {th }}$ day of gestation produced statistically significant incidence of severe malformations. We observed dead or resorptions in $10.5 \%$ of foetuses.

Dawrant et al, $2007^{9}$ reported that administration of adriamycine at $6 \mathrm{mg} / \mathrm{kg}$ on $7^{\text {th }}$ and $8^{\text {th }}$ gestational day had the most teratogen effect, with $80 \%$ of the foetuses having 3 or more VACTERL anomalies e.g. anorectal malformations $100 \%$, tracheo-esophageal malformations 50\%, bladder agenesis /bilateral hydronephrosis $100 \%$, right sided aortic arches $58 \%$.

Adriamycine administration in the chick model produces spectrum of anomalies like exencephaly (Exencephaly, wherein the brain is located outside of the skull). This condition is usually found in embryos as an early stage of anencephaly. As an exencephalic pregnancy progresses, the neural tissue gradually degenerates) and anophthalmia (Mort ell et al, 2003). ${ }^{10}$ As stated by the Singh and Padmanabhan(1978), ${ }^{11}$ central nervous system defects can be induced in experimental animals by variety of agents like nutritional deficiency, ionising radiations, maternal viral infections, chemicals and therapeutic agents. Microcephaly and intra-uterine growth retardation (IUGR) due to anoxia induced by uterine artery clumping was noted by Chinara (1980). ${ }^{12}$ The present study also showed intra-uterine growth retardation (IUGR) and microcephaly; support the study of mortell and chinara.

The Sonic Hedgehog (Shh) is an important signal transduction pathway in early embryonic development and it is expressed in notochord \& floor plate of the neural tube, endodermal epithelium and other areas during development of embryos (Ding et al, $1998 .{ }^{13} \mathrm{Bit}$ good et al, 1995. ${ }^{14}$ Sukegawa et al, 2000 ${ }^{15}$ ). Correct Shh signalling between tissues in early embryo is vital for normal patterning like notochord to gut, floor plate, motor neuron, somite and limb development (Bumcrot $\&$ McMohan, $1995 .{ }^{16} \mathrm{Kim}$ et al $1997^{17}$ ). The genetic sequence of Shh is practically identical in mice, rat and human (Gerhart, $1998 \& 1999^{18}$ ). Chiang $(1996)^{19}$ was the first to link mammalian disease with abnormal Shh function. He reported that the mice suffering from homozygous deletion of Shh leads to spinal cord, neural tube and limb anomalies.

Mice are the foremost mammal studied by developmental biologist. The teratogenic effect of adriamycine in the rat model, and more recently in the mouse has provided a reliable, easily reproducible method of studying the embryology and molecular biology for range of complex congenital anomalies.

\section{Conclusion}

In the present study, it was found that the teratogenicity was produced in developing mice embryos by injecting doxorubicin $3 \mathrm{mg} / \mathrm{kg}$ body weight into the peritoneal cavity of the pregnant albino mice on $8^{\text {th }}$ day of gestation. The brain of treated foetuses showed microcephaly. Histological examination of cerebrum and cerebellum showed degeneration and aggregation of neuronal cells and significant derangement of normal architecture.

Funding: No funding sources.

Conflict of interest: None declared.

\section{References}

1. Nishimura H. Chemistry and Prevention of Congenital Anomalies (American Lectures in Living Chemistry) Edited by I N Kugelmass. Published by Charles C. Thomas, Springfield Illinois, U S A,1964

2. Daniel KL, Honein MA, Moore CA. Sharing prescription medication among teenage girls: potential danger to unplanned/undiagnosed pregnancies. Paediatrics 2003;111:1167-70.

3. Naomi TS, Ipscomb LE, Brewer RD, Gilbert BC. Binge drinking in the preconception period and the risk of unintended pregnancy: implication for women and their children, Paediatr 2003;111:1136-41.

4. Goodman and Gilman's. The pharmacological basis of therapeutics, $11^{\text {th }}$ ed, McGraw-hill, 2006;1357-59.

5. Meyers CE. Role of iron in anthracycline, action in organ directed toxities of anti- cancer drugs. Nijhoff, Boston.1998:17-30.

6. Gewirtz DA. A critical evaluation of the mechanisms of action proposed for the ant-tumour effects of the anthracycline antibiotics adriamycine and daunorubicin. Biochem. Pharmacol 1999;57:727-41.

7. Orford JE and Cass DT. Dose response relationship between adriamycine and birth defects in a rat model of VATER association. J Paediatr Surg 1999;34:392-98.

8. Gillick J, Mortell A, Dawrant M, Giles S, Bannigan, Puri $\mathrm{P}$. The adriamycine rat/mouse model and its importance to the paediatric surgeon. Paediatr Surg Int 2008;24:11318.

9. Dawrant MJ, Giles S, Bannigan J, Puri P. Adriamycine mouse model: a variable but reproducible model of trachea-oesophageal malformations. Paediatr Surg Int 2007;23:469-72.

10. Mortell A, Dawrant M, Giles S, Bannigan, Puri P. Adriamycine effects on the chick embryo. Pediatr Surg Int 2003;9(5):359-64.

11. Singh S, Padamanabhan R, Effect of chlorpromazine on developing brain. A morphological and histological study. Cong Anomalies 1978;18:252.

12. Chinara PK. Effect of experimental ischaemic anoxia on the developing brain of rat. M.S. thesis submitted to Banaras Hindu University, Varanasi, India. 1980.

13. Ding Q, Motoyama J, Gasca S, Sasaki M, Mo R, Rossant J, Hui C. Diminished Soni Hedgehog signalling and lack of floor plate differentian in Gli2 mutant mice. Development 1998;125:2533-43. 
14. Bitgood MJ, and McMahon AP. Hedgehog and BMP genes are co expressed at many diverse sites of cell-cell interaction in the mouse embryo. Dev Biol 1995;172:12638.

15. Sukegawa A, Narita T, Kameda T, Saitoh K, Nohno T, Iba H, Yasugui S, Fukuda K. The concentric structure of the developing gut is regulated by Sonic hedgehog derived from endodermal epithelium. Development 2000;127(9):1971-80.

16. Bumcrot DA and McMahon AP. Somite differentiation, sonic signals somites. Current Bio 1995;5:612-14.

17. Kim SK, Hebrok M, Melton DA. Notochord to endoderm signalling is required for pancreases development. Development 1997;124:4243-52.

18. Gerhart J. Warkany lecture: signalling pathways in development. Teratology 1999,60(4):226-39.

19. Chiang C. Cyclopia and defective axial patterning in mice lacking sonic hedgehog gene function. Nature 1996;383(6599):407-13.

How to cite the article: Singh Y., Ramji, Shah G. Effects of doxorubicin on the developing brain of albino mice embryos. Indian $J$ Anat Surg Head Neck Brain 2018;4(3):75-78. 